OPEN ACCESS

Edited by:

Karen M. Vasquez,

The University of Texas at Austin, USA

Reviewed by:

Ruslan Sadreyev,

Howard Hughes Medical Institute,

Albino Bacolla

The University of Texas MD Anderson

Cancer Center, USA

${ }^{*}$ Correspondence:

Hiroki Kurahash

kura@fujita-hu.ac.jp

Specialty section:

This article was submitted to Bioinformatics and Computational

Biology,

a section of the journa

Frontiers in Genetics

Received: 06 May 2016

Accepted: 28 June 2016

Published: 12 July 2016

Citation:

Inagaki $H$, Kato $T$, Tsutsumi $M$, Ouchi Y, Ohye $T$ and Kurahashi $H$

(2016) Palindrome-Mediated

Translocations in Humans: A New

Mechanistic Model for Gross

Chromosomal Rearrangements.

Front. Genet. 7:125.

doi: 10.3389/fgene.2016.00125

\section{Palindrome-Mediated Translocations in Humans: A New Mechanistic Model for Gross Chromosomal Rearrangements}

\author{
Hidehito Inagaki ${ }^{1,2}$, Takema Kato ${ }^{1}$, Makiko Tsutsumi ${ }^{1}$, Yuya Ouchi ${ }^{2}$, Tamae Ohye ${ }^{3}$ and \\ Hiroki Kurahashi ${ }^{1,2 *}$ \\ ${ }^{1}$ Division of Molecular Genetics, Institute for Comprehensive Medical Science, Fujita Health University, Toyoake, Japan, \\ ${ }^{2}$ Genome and Transcriptome Analysis Center, Fujita Health University, Toyoake, Japan, ${ }^{3}$ Department of Molecular Laboratory \\ Medicine, Faculty of Medical Technology, School of Health Science, Fujita Health University, Toyoake, Japan
}

Palindromic DNA sequences, which can form secondary structures, are widely distributed in the human genome. Although the nature of the secondary structure-single-stranded "hairpin" or double-stranded "cruciform"-has been extensively investigated in vitro, the existence of such unusual non-B DNA in vivo remains controversial. Here, we review palindrome-mediated gross chromosomal rearrangements possibly induced by non-B DNA in humans. Recent advances in next-generation sequencing have not yet overcome the difficulty of palindromic sequence analysis. However, a dozen palindromic AT-rich repeat (PATRR) sequences have been identified at the breakpoints of recurrent or non-recurrent chromosomal translocations in humans. The breakages always occur at the center of the palindrome. Analyses of polymorphisms within the palindromes indicate that the symmetry and length of the palindrome affect the frequency of the de novo occurrence of these palindrome-mediated translocations, suggesting the involvement of non-B DNA. Indeed, experiments using a plasmid-based model system showed that the formation of non-B DNA is likely the key to palindrome-mediated genomic rearrangements. Some evidence implies a new mechanism that cruciform DNAs may come close together first in nucleus and illegitimately joined. Analysis of PATRR-mediated translocations in humans will provide further understanding of gross chromosomal rearrangements in many organisms.

Keywords: palindrome, inverted repeat, cruciform, chromosomal translocation, gross chromosomal rearrangement

\section{INTRODUCTION}

DNA palindromes consist of two units of identical sequences connected in an inverted position with respect to each other. In palindromes, the sequences on the complementary strands read the same in either direction. In other words, the complementary sequence appears in the same strand in an inverted orientation. Palindromic DNA can consequently form specific tertiary structures,

Abbreviations: PATRR, palindromic AT-rich repeat. 
namely, single-stranded "hairpin" or double-stranded "cruciform" DNA. Such unusual DNA tertiary structures are called non-B DNA structures (Sinden, 1994; Wang and Vasquez, 2014). These non-B DNA structures are presumed to be generated in a cell under specific situations, although their in vivo existence is still a controversial subject.

Hairpin structures can be formed when the double helix DNA is dissociated into single-stranded DNA molecules at the palindrome. Such single-stranded DNA might occur during DNA or RNA synthesis during replication or transcription. On the other hand, cruciform formation starts from unwinding of the center of the double-stranded palindromic DNA, followed by extrusion at the center of the palindrome to form an intra-strand base-paring of each strand. As the DNA unwinds, the cruciform gets bigger. Cruciform formation requires an under-twisted state, that is, negative superhelicity, of the DNA. Such unusual DNA structure itself could have an impact on DNA replication, repair, transcription, or other important biological pathways (Inagaki and Kurahashi, 2013). The DNA regions that potentially form non-B DNA structures often manifest genomic instability that induces gross chromosomal rearrangements (Pearson et al., 2005; Tanaka et al., 2005; Maizels, 2006; Raghavan and Lieber, 2006; Mirkin, 2007; McMurray, 2010).

\section{PALINDROME-MEDIATED CHROMOSOMAL TRANSLOCATIONS IN HUMAN SPERM}

The best-studied palindromic sequences are the breakpoint sequences of the constitutional $t(11 ; 22)(q 23 ; q 11.2)$ translocation, a well-known recurrent non-Robertsonian translocation in humans. Balanced carriers are healthy but often have reproductive problems such as infertility, recurrent pregnancy loss, and offspring with Emanuel syndrome (Carter et al., 2009; Ohye et al., 2014; Emanuel et al., 2015). Breakpoint analysis of $11 \mathrm{q} 23$ and $22 \mathrm{q} 11$ revealed that these regions contain a large palindrome of hundreds of base pairs that is extremely AT-rich (Kurahashi et al., 2000a, 2007; Edelmann et al., 2001; Kurahashi and Emanuel, 2001a; Tapia-Páez et al., 2001). These so-called palindromic AT-rich repeats (PATRRs) have been identified at both breakpoints on chromosomes 11 and 22 and are named PATRR11 and PATRR22, respectively. These PATRRs have several features in common. Both are several hundred base pairs in length and have greater than 90\% AT content. They manifest nearly perfect palindromes without spacer regions but share little homology between the two chromosomes.

The most prominent feature of the $t(11 ; 22)$ translocation is that de novo translocations frequently arise at a similar breakpoint location. Translocation-specific PCR with primers flanking the breakpoints on chromosomes 11 and 22 can detect all of the $t(11 ; 22)$ junction sequence in the translocation carriers (Kurahashi et al., 2000b). We performed PCR at the single-molecule detection level using sperm DNA from normal healthy men with the $46, \mathrm{XY}$ karyotype as template. Some DNA aliquots tested positive for $\mathrm{t}(11 ; 22)$-specific PCR products while others were negative, suggesting that the PCR detected de novo $\mathrm{t}(11 ; 22)$ translocations (Kurahashi and Emanuel, 2001b). The frequency was about one in 10,000. However, when the DNA of blood cells or cheek swab cells from the same men was analyzed, no translocation could be found. Furthermore, all of the lymphoblastoid cell lines or cultured fibroblasts examined also tested negative in PCR analysis. These results imply that the $\mathrm{t}(11 ; 22)$ translocation arises in a sperm-specific fashion. There is no evidence for the occurrence of the $t(11 ; 22)$ translocation during female gametogenesis because of the limited availability of human oocytes for testing. However, in de novo $\mathrm{t}(11 ; 22)$ families, analysis of the parental origin of the translocation chromosomes using the polymorphic feature of PATRR11 and PATRR22 revealed that all of the de novo $t(11 ; 22)$ translocations were of paternal origin, supporting a hypothesized sperm-specific mechanism of $\mathrm{t}(11 ; 22)$ translocation formation (Ohye et al., 2010).

\section{DNA SECONDARY STRUCTURE IN THE PALINDROME: HAIRPIN OR CRUCIFORM}

What is behind the sperm-specific occurrence of the PATRRmediated translocation? It is not unreasonable to discuss the mechanism leading to the $t(11 ; 22)$ translocation in the context of DNA secondary structure. The DNA secondary structure at the PATRR is potentially evidenced by the fact that a polymorphism within the PATRR affects the de novo $\mathrm{t}(11 ; 22)$ translocation frequency (Kato et al., 2006; Tong et al., 2010). PATRR11 and PATRR22 have size polymorphisms in the general population due to deletion within the palindromic region. Carriers with long symmetric alleles preferably produce de novo $t(11 ; 22)$ translocations more frequently than carriers with PATRR asymmetric arms. These data indirectly but strongly implicate the presence of DNA secondary structure during translocation formation.

One hypothesis to explain the sperm specificity of the $t(11 ; 22)$ translocation is that it develops during DNA replication. Sperm production involves many cell divisions, each requiring DNA replication. During DNA replication, single-stranded DNA is generated in the template DNA for the synthesis of not only the lagging strand DNA, but also the leading strand (Azeroglu et al., 2014). When the replication fork comes to the palindromic region, a long single-stranded DNA is formed, inducing the formation of a single-stranded hairpin structure. The stalling of the replication fork produces DNA breakage at the palindromic region that can potentially induce translocations.

Because the germ stem cells in men replicate about 23 times per year, mature sperm from older men have undergone a greater number of replication cycles. The frequency of de novo point mutations in sperm cells increases according to the age of the sample donor (Crow, 2000; O'Roak et al., 2012). If the $t(11 ; 22)$ translocation is mediated by replication, the frequency of the de novo $\mathrm{t}(11 ; 22)$ translocation should be higher in sperm from older men than in younger men for a similar reason. A previous analysis of the $t(11 ; 22)$ translocation 
suggested, however, that there is no tendency for an increase in $t(11 ; 22)$ translocation frequency in the sperm of older men (Kato et al., 2007).

To determine the involvement of DNA replication in translocation formation, we established a model system for the $\mathrm{t}(11 ; 22)$ translocation in cultured cells by using plasmids harboring PATRR11 or PATRR22 (Inagaki et al., 2009). Both plasmids were transfected into the HEK293 human cell line and we monitored the fusion of the different plasmids at each PATRR using GFP expression or translocation-specific PCR (Figure 1A). The results indicated that a translocation-like reaction took place. In this reaction, both PATRRs were cleaved at the center of the palindrome and joined via non-homologous endjoining in a similar manner to the human $t(11 ; 22)$ translocation. Crucially, the plasmids had no replication origin for human cells, which means that the translocation took place without DNA replication.

\section{POST-MEIOSIS HYPOTHESIS FOR PATRR-MEDIATED TRANSLOCATIONS}

On the other hand, it is possible that the translocation is mediated by another secondary structure, the DNA cruciform. In our model system, the plasmids were purified from Escherichia coli using a standard alkaline lysis method. Plasmid DNA isolated from $E$. coli has a strong negative superhelicity. If the plasmid has a palindromic region, the negative superhelicity facilitates cruciform extrusion (Kurahashi et al., 2004). Under an alkaline condition that induces denaturation of the plasmid DNA during purification, most of the PATRR-harboring plasmids extrude cruciform structures. Via the use of a non-denaturing condition and subsequent topoisomerase treatment, such superhelicity was relieved before cruciform extrusion. In this way, we can prepare different topoisomers of the same plasmid, both cruciformextruded DNA and not extruded DNA. We tested the effect
A
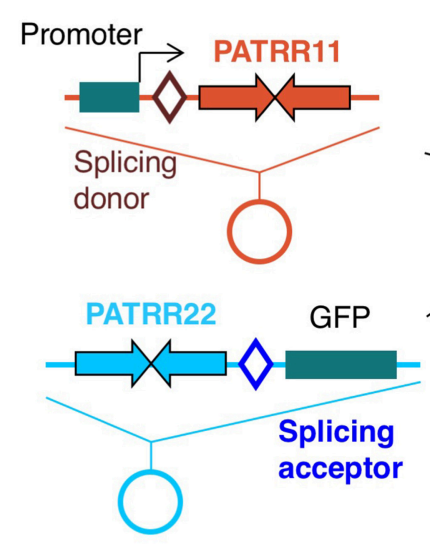

Fusion of two plasmids

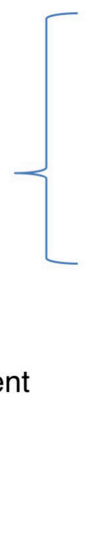

Cruciform

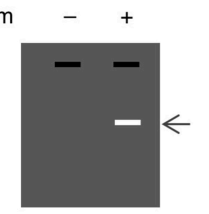

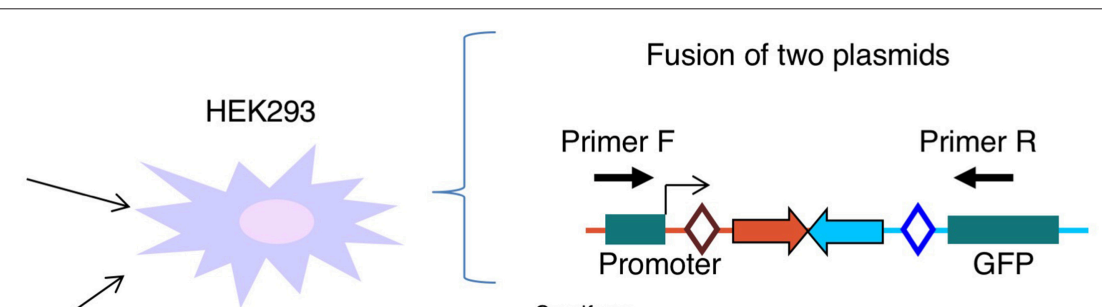

PCR detection

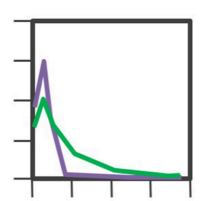

GFP in flow cytometry

B

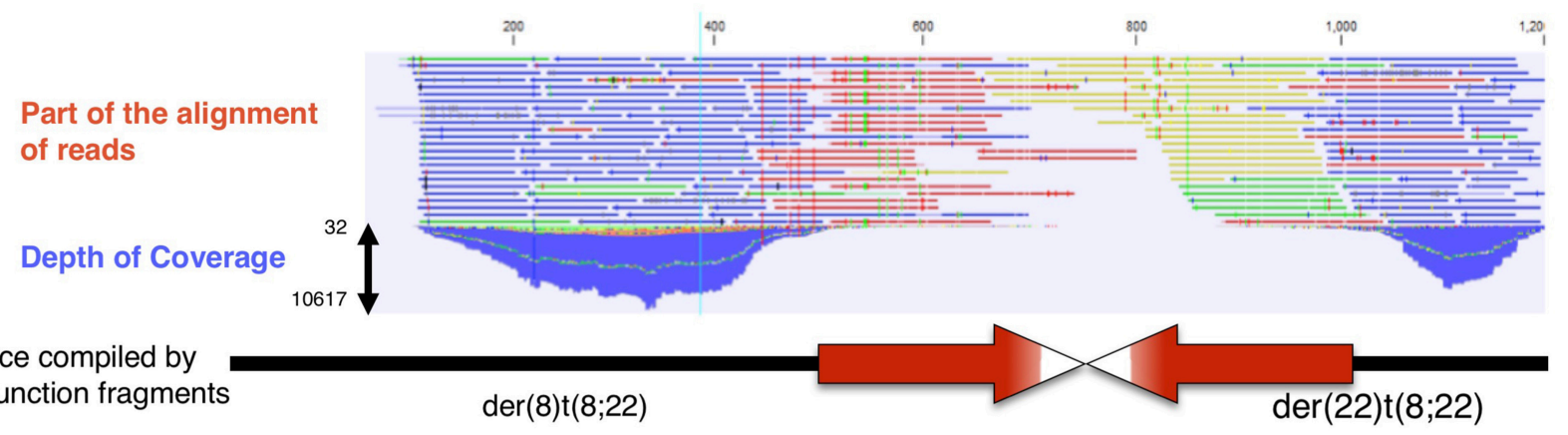

$t(8 ; 22)$ junction fragments

$\operatorname{der}(8) t(8 ; 22)$

$\operatorname{der}(22) t(8 ; 22)$

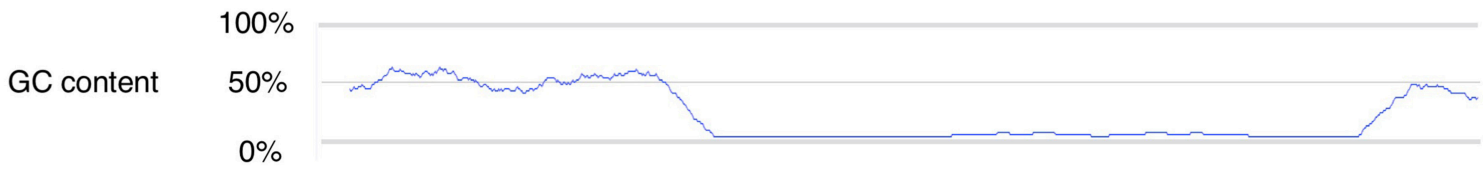

FIGURE 1 | (A) Translocation model system. Two plasmids, one harboring a promoter, splicing donor, and PATRR11, and the other carrying PATRR22, a splicing acceptor, and a coding region of the GFP gene, were simultaneously transfected into HEK293 cells. After $24 \mathrm{~h}$, fusion molecules generated by joining of the PATRR11 and PATRR22 at the center were detected by PCR or GFP-positive cells were monitored by flow cytometry (Inagaki et al., 2013). (B) Determination of the PATRR8 sequence by next-generation sequencing. Although the depth of the coverage was low at the center of the palindrome, massive parallel sequencing was able to fill the entire region of the palindrome (Mishra et al., 2014). 
of the cruciform on the translocation-like reaction in the cell using a mixture of cruciform and non-cruciform plasmids. The frequency of the translocation-like reaction was found to depend on the proportion of the cruciform-extruded plasmid DNA (Figure 1A; Inagaki et al., 2009). These results suggest that cruciform extrusion at the palindromic region induces PATRRmediated translocation.

Notably however, in living cells the conversion of a DNA structure from that of standard B DNA to cruciform DNA is unlikely to occur under normal physiological conditions from a point of view of thermodynamics. Cruciform extrusion at the palindromic region occurs only when the DNA has strong free negative superhelicity. Theoretically, such superhelicity would potentially occur only at the post-meiosis stage in late spermatogenesis. At this developmental stage, histones are replaced by protamines to reduce the cell size (Gaucher et al., 2010). During histone removal, DNA has a transient excess of negative supercoiling, which might induce cruciform extrusion at the palindromic DNA that leads to translocation formation (Boissonneault, 2002). It is highly possible that PATRR-mediated translocations occur at this developmental stage of spermatogenesis (Kurahashi et al., 2010).

Although the post-meiosis hypothesis is captivating, there is some evidence contradicting this hypothesis. One example is the presence of somatic mosaicism of the $t(11 ; 22)$ translocation and normal cells in humans (Kurahashi et al., 2000b). This indicates that the $t(11 ; 22)$ translocation in this case was generated during the mitotic cell cycles after fertilization. Another example is the existence of de novo cases of Emanuel syndrome (Kurahashi et al., 2000b). Emanuel syndrome generally occurs via 3:1 segregation of the translocation chromosomes during meiosis I in a $\mathrm{t}(11 ; 22)$ balanced carrier. However, a de novo Emanuel syndrome case would have arisen via 3:1 segregation of the $t(11 ; 22)$ chromosomes during the pre-meiotic somatic cell cycles of gametogenesis.

\section{ANALYSIS OF THE PATRR BY NEXT-GENERATION SEQUENCING}

In addition to PATRR11 and PATRR22, a dozen PATRRs have been found at other translocation breakpoints. A recurrent $\mathrm{t}(17 ; 22)(\mathrm{q} 11.2 ; \mathrm{q} 11.2)$ translocation was found in neurofibromatosis type 1 patients (Kehrer-Sawatzki et al., 2002; Kurahashi et al., 2003). Identification of another recurrent translocation between 8q24.1 and 22q11.2 led to the definition of a new malformation syndrome (Sheridan et al., 2010). Other PATRRs at 4q35.1, 1p21.2, 3p14, and 9p21 were identified at the breakpoints of non-recurrent constitutional translocations (Nimmakayalu et al., 2003; Gotter et al., 2004; Tan et al., 2013; Kato et al., 2014). These PATRRs share little homology but have features of AT-richness and symmetric palindromic structure in common. Intriguingly, all of the palindrome-mediated translocations occur between one PATRR and another PATRR.

We attempted to perform genome-wide screening of de novo PATRR-mediated translocations to identify unknown PATRRs using next-generation sequencing. We used the PATRR22 sequence as bait for the detection of any unknown sequences next to the PATRR22 due to de novo translocation. However, several difficulties were encountered. We could not confirm the presence of the translocation because most of the PATRRmediated non-recurrent translocations occurred at a frequency below the detection levels of PCR using sperm from normal healthy donors. Furthermore, we could not analyze the novel translocation junction because the partner sequence could not be mapped to the human reference sequence. None of the translocation-related PATRR sequences identified to date appear in the human genome assembly.

Although the genome projects for many organisms including humans determined their complete nucleotide sequences, difficult-to-sequence regions remain as "gaps." Recent novel sequencing technologies have made it possible to access some of the gaps and provide more precise genomic data (Chaisson et al., 2015). The PATRR sequences do not appear even in such human reference databases. Palindrome sequences are one such type of a difficult-to-sequence region due to a "triple whammy" of factors affecting sequence analysis: the palindromic sequences are generally refractory to cloning to vectors, PCR amplification, and Sanger sequencing (Inagaki et al., 2005; Lewis et al., 2005). These features are due to the nature of the palindromic sequence itself. The longer the palindrome, the more difficult its analysis.

\section{DEEP SEQUENCING OF THE PATRR REGION HAS GENERATED A NOVEL HYPOTHESIS}

We applied next-generation sequencing technology to determine the complete sequence of the PATRR on $8 \mathrm{q} 24$, which was found at the breakpoint of $\mathrm{t}(8 ; 22)$ (q24;q11) (Mishra et al., 2014). Sequencing of a random sheared library of PCR products and reconstruction of the original DNA via the computer-aided alignment of thousands of DNA molecules allowed us to successfully determine the entire PATRR8 (Figure 1B). The next-generation sequencing method does not require cloning and can directly analyze numerous DNA molecules at the same time. Although this strategy still requires PCR to amplify the single molecules and improve signal detection, the random digestion of the palindrome increases the chance of generating asymmetric cleavages of the palindromic center, which improves the PCR efficiency.

By means of this system, we determined the entire PATRR8 sequence, even at the center of the symmetry. This PATRR8 sequence allowed us to develop $t(8 ; 22)$-specific PCR primers to analyze the junction fragments. The breakage always occurred at the center of the PATRR8 and PATRR22. The fusion was accompanied by the deletion of small nucleotides at the breakpoint regions. Interestingly, the nucleotide sequences around the junctions are identical between the $\operatorname{der}(8)$ and der(22) (Mishra et al., 2014). This cannot happen if the two breakages at the PATRR8 and PATRR22 occur independently and are followed by random nucleotide deletion at the breakage ends. This implies coordinated processing of PATRR8 and 
PATRR22. Similar features of identical junctions in the two derivative chromosomes were also found in $t(11 ; 22)$ and $t(17 ; 22)$ (Kurahashi and Emanuel, 2001a; Kurahashi et al., 2003).

The standard models for gross chromosomal rearrangement include the breakage-first model and the contact-first model (Misteli and Soutoglou, 2009). In the breakage-first model, two DNA breaks located far from each other in the nucleus seek each other out to form a fusion chromosome. The artificial translocation model for the observation of the spatiotemporal chromosomal location in living cells revealed the dynamic movement of chromosomes after their breakage (Roukos et al., 2013). On the other hand, according to the contactfirst model, translocation takes place between two closely located sites in the nucleus. Our previous data suggested that PATRR11 and PATRR22 are closer than other control chromosomal regions, indicating that this shorter distance might partly contribute to the recurrent nature of the $t(11 ; 22)$ translocation (Ashley et al., 2006). However, these two models do not explain specific translocations between two PATRRs.

Again, the identical sequences of the two derivative chromosomes imply that the two DNA breakage sites are unlikely to have been processed independently. The two derivative chromosomes were likely to be generated in a coordinated manner. Taken together, in the case of a PATRR-mediate translocation, PATRR appears to extrude cruciform structures at some stage during spermatogenesis. The two cruciform DNA molecules seek each other out and finally join together (Figure 2). In our translocation model system in cultured cells described above, the data suggested that two cleavage processes-cleaved diagonal cleavage of the cruciform structure and cleavage of the tip of the hairpin structure-are involved in translocation development (Inagaki et al., 2013). Our data also suggest that the pathway involves the participation of Artemis and ligase IV, which are components of the $\mathrm{V}(\mathrm{D}) \mathrm{J}$ recombination system that act by bringing two chromosomal sites close together

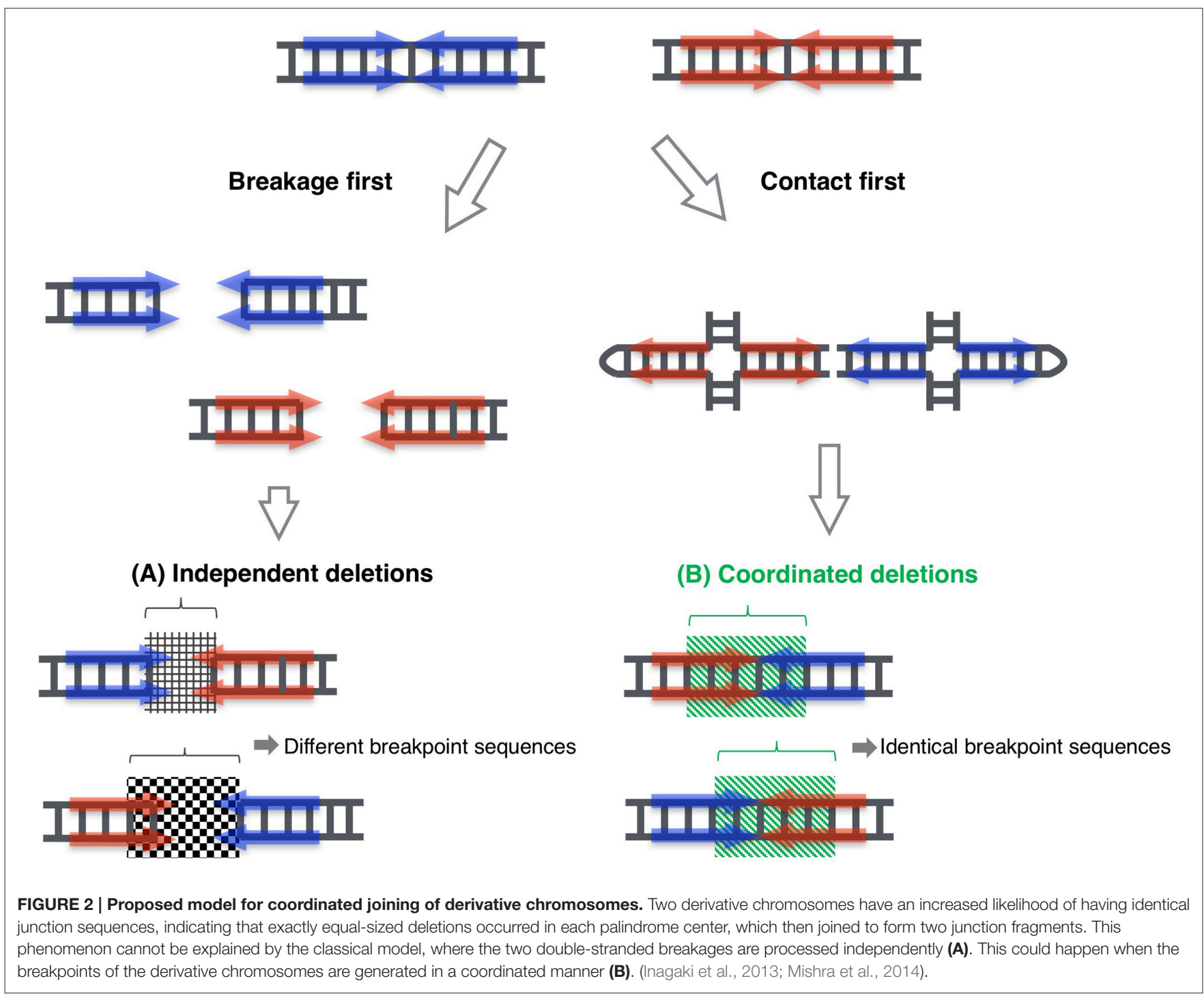


and connecting them. In $V(D) J$ recombination, RAG1 and RAG2 proteins bind the two cleavage sites to hold the resulting ends, both of which are specific for the V(D)J recombination machinery in lymphocytes. Similar mechanism is known in a DNA repair system of non-homologous end joining, in which Ku70/80 holds the two broken end until the subsequent repair machinery associate to process and join the ends (Deriano and Roth, 2013). Artemis and ligase IV as well as DNA-PK and other factors also participate in the joining reactions. It is possible that a part of such systems, or other novel factors might be involved in the contact between the two extruded cruciform structures and in keeping them in position during processing until the two derivative chromosomes are generated. We are now investigating how two cruciform DNA molecules come close together to elucidate the third mechanistic model that leads to recurrent chromosomal translocations in humans. Such investigation of dynamics of the cruciforms in nuclei will shed light on the role of non-B DNAs in gross chromosomal rearrangements in other eukaryotes.

\section{REFERENCES}

Ashley, T., Gaeth, A. P., Inagaki, H., Seftel, A., Cohen, M. M., Anderson, L. K., et al. (2006). Meiotic recombination and spatial proximity in the etiology of the recurrent t(11;22). Am. J. Hum. Genet. 79, 524-538. doi: 10.1086/507652

Azeroglu, B., Lincker, F., White, M. A., Jain, D., and Leach, D. R. (2014). A perfect palindrome in the Escherichia coli chromosome forms DNA hairpins on both leading- and lagging-strands. Nucleic Acids Res. 42, 13206-13213. doi: $10.1093 /$ nar/gku1136

Boissonneault, G. (2002). Chromatin remodeling during spermiogenesis: a possible role for the transition proteins in DNA strand break repair. FEBS Lett. 514, 111-114. doi: 10.1016/S0014-5793(02)02380-3

Carter, M. T., St Pierre, S. A., Zackai, E. H., Emanuel, B. S., and Boycott, K. M. (2009). Phenotypic delineation of Emanuel syndrome (supernumerary derivative 22 syndrome): clinical features of 63 individuals. Am. J. Med. Genet. A. 149, 1712-1721. doi: 10.1002/ajmg.a.32957

Chaisson, M. J., Huddleston, J., Dennis, M. Y., Sudmant, P. H., Malig, M., Hormozdiari, F., et al. (2015). Resolving the complexity of the human genome using single-molecule sequencing. Nature 517, 608-611. doi: 10.1038 /nature 13907

Crow, J. F. (2000). The origins, patterns and implications of human spontaneous mutation. Nat. Rev. Genet. 1, 40-47. doi: 10.1038/35049558

Deriano, L., and Roth, D. B. (2013). Modernizing the nonhomologous end-joining repertoire: alternative and classical NHEJ share the stage. Annu. Rev. Genet. 47, 433-455. doi: 10.1146/annurev-genet-110711-155540

Edelmann, L., Spiteri, E., Koren, K., Pulijaal, V., Bialer, M. G., Shanske, A., et al. (2001). AT-rich palindromes mediate the constitutional $\mathrm{t}(11 ; 22)$ translocation. Am. J. Hum. Genet. 68, 1-13. doi: 10.1086/316952

Emanuel, B. S., Zackai, E. H., and Medne, L. (2015). "Emanuel syndrome," in GeneReviews, eds R. A. Pagon, M. P. Adam, H. H. Ardinger, S. E. Wallace, A. Amemiya, L. J. H. Bean, T. D. Bird, C. T. Fong, H. C. Mefford, R. J. H. Smith, and K. Stephens (Seattle, DC: University of Washington).

Gaucher, J., Reynoird, N., Montellier, E., Boussouar, F., Rousseaux, S., and Khochbin, S. (2010). From meiosis to postmeiotic events: the secrets of histone disappearance. FEBS J. 277, 599-604. doi: 10.1111/j.1742-4658.2009.07504.x

Gotter, A. L., Shaikh, T. H., Budarf, M. L., Rhodes, C. H., and Emanuel, B. S. (2004). A palindrome-mediated mechanism distinguishes translocations involving LCR-B of chromosome 22q11.2. Hum. Mol. Genet. 13, 103-115. doi: 10.1093/hmg/ddh004

Inagaki, H., and Kurahashi, H. (2013). "Cruciform DNA," in Brenner's Encyclopedia of Genetics, 2nd Edn., eds S. Maloy and K. Hughes (London, UK: Elsevier), 241-243.

\section{AUTHOR CONTRIBUTIONS}

HI and HK wrote the initial manuscript. All authors discussed the text and commented on the manuscript.

\section{FUNDING}

This study was supported by Grants-in-Aid for Scientific Research (HI, HK) and the MEXT-Supported Program for the Strategic Research Foundation at Private Universities (HK) from the Ministry of Education, Culture, Sports, Science, and Technology of Japan, and a Health and Labour Sciences Research Grant (HK) from the ministry of Health, Labour and Welfare of Japan.

\section{ACKNOWLEDGMENTS}

We thank Dr. Beverly S. Emanuel and the members of our laboratory for discussion and advice on this manuscript.

Inagaki, H., Ohye, T., Kogo, H., Kato, T., Bolor, H., Taniguchi, M., et al. (2009) Chromosomal instability mediated by non-B DNA: cruciform conformation and not DNA sequence is responsible for recurrent translocation in humans. Genome Res. 19, 191-198. doi: 10.1101/gr.079244.108

Inagaki, H., Ohye, T., Kogo, H., Tsutsumi, M., Kato, T., Tong, M., et al. (2013). Two sequential cleavage reactions on cruciform DNA structures cause palindrome-mediated chromosomal translocations. Nat. Commun. 4:1592. doi: $10.1038 /$ ncomms 2595

Inagaki, H., Ohye, T., Kogo, H., Yamada, K., Kowa, H., Shaikh, T. H., et al. (2005). Palindromic AT-rich repeat in the NF1 gene is hypervariable in humans and evolutionarily conserved in primates. Hum. Mutat. 26, 332-342. doi: 10.1002/humu.20228

Kato, T., Franconi, C. P., Sheridan, M. B., Hacker, A. M., Inagakai, H., Glover, T. W., et al. (2014). Analysis of the $\mathrm{t}(3 ; 8)$ of hereditary renal cell carcinoma: a palindrome-mediated translocation. Cancer Genet. 207, 133-140. doi: 10.1016/j.cancergen.2014.03.004

Kato, T., Inagaki, H., Yamada, K., Kogo, H., Ohye, T., Kowa, H., et al. (2006). Genetic variation affects de novo translocation frequency. Science 311, 971. doi: $10.1126 /$ science. 1121452

Kato, T., Yamada, K., Inagaki, H., Kogo, H., Ohye, T., Emanuel, B. S., et al. (2007). Age has no effect on de novo constitutional $\mathrm{t}(11 ; 22)$ translocation frequency in sperm. Fertil. Steril. 88, 1446-1448. doi: 10.1016/j.fertnstert.2007.01.019

Kehrer-Sawatzki, H., Assum, G., and Hameister, H. (2002). Molecular characterisation of $\mathrm{t}(17 ; 22)(\mathrm{q} 11.2 ; \mathrm{q} 11.2)$ is not consistent with $\mathrm{NF} 1$ gene duplication. Hum. Genet. 111, 465-467. doi: 10.1007/s00439-002-0794-3

Kurahashi, H., and Emanuel, B. S. (2001a). Long AT-rich palindromes and the constitutional t(11;22) breakpoint. Hum. Mol. Genet. 10, 2605-2617. doi: $10.1093 / \mathrm{hmg} / 10.23 .2605$

Kurahashi, H., and Emanuel, B. S. (2001b). Unexpectedly high rate of de novo constitutional $\mathrm{t}(11 ; 22)$ translocations in sperm from normal males. Nat. Genet. 29, 139-140. doi: 10.1038/ng1001-139

Kurahashi, H., Inagaki, H., Hosoba, E., Kato, T., Ohye, T., Kogo, H., et al. (2007). Molecular cloning of a translocation breakpoint hotspot in 22q11. Genome Res. 17, 461-469. doi: 10.1101/gr.5769507

Kurahashi, H., Inagaki, H., Ohye, T., Kogo, H., Tsutsumi, M., Kato, T., et al. (2010). The constitutional $\mathrm{t}(11 ; 22)$ : implications for a novel mechanism responsible for gross chromosomal rearrangements. Clin. Genet. 78, 299-309. doi: 10.1111/j.1399-0004.2010.01445.x

Kurahashi, H., Inagaki, H., Yamada, K., Ohye, T., Taniguchi, M., Emanuel, B. S., et al. (2004). Cruciform DNA structure underlies the etiology for palindrome-mediated human chromosomal translocations. J. Biol. Chem. 279, 35377-35383. doi: 10.1074/jbc.M400354200 
Kurahashi, H., Shaikh, T. H., Hu, P., Roe, B. A., Emanuel, B. S., and Budarf, M. L. (2000a). Regions of genomic instability on $22 \mathrm{q} 11$ and $11 \mathrm{q} 23$ as the etiology for the recurrent constitutional t(11;22). Hum. Mol. Genet. 9, 1665-1670. doi: 10.1093/hgm/9.11.1665

Kurahashi, H., Shaikh, T. H., Zackai, E. H., Celle, L., Driscoll, D. A., Budarf, M. L., et al. (2000b). Tightly clustered 11q23 and 22q11 breakpoints permit PCRbased detection of the recurrent constitutional t(11;22). Am. J. Hum. Genet. 67, 763-768. doi: 10.1086/303054

Kurahashi, H., Shaikh, T., Takata, M., Toda, T., and Emanuel, B. S. (2003). The constitutional $\mathrm{t}(17 ; 22)$ : another translocation mediated by palindromic AT-rich repeats. Am. J. Hum. Genet. 72, 733-738. doi: 10.1086/3 68062

Lewis, S. M., Chen, S., Strathern, J. N., and Rattray, A. J. (2005). New approaches to the analysis of palindromic sequences from the human genome: evolution and polymorphism of an intronic site at the NF1 locus. Nucleic Acids Res. 33, e186. doi: $10.1093 /$ nar/gni189

Maizels, N. (2006). Dynamic roles for G4 DNA in the biology of eukaryotic cells. Nat. Struct. Mol. Biol. 13, 1055-1059. doi: 10.1038/nsmb1171

McMurray, C. T. (2010). Mechanisms of trinucleotide repeat instability during human development. Nat. Rev. Genet. 11, 786-799. doi: 10.1038/ $\operatorname{nrg} 2828$

Mirkin, S. M. (2007). Expandable DNA repeats and human disease. Nature 447, 932-940. doi: 10.1038/nature05977

Mishra, D., Kato, T., Inagaki, H., Kosho, T., Wakui, K., Kido, Y., et al. (2014). Breakpoint analysis of the recurrent constitutional $\mathrm{t}(8 ; 22)(\mathrm{q} 24.13 ; \mathrm{q} 11.21)$ translocation. Mol. Cytogenet. 7:55. doi: 10.1186/s13039-0140055-x

Misteli, T., and Soutoglou, E. (2009). The emerging role of nuclear architecture in DNA repair and genome maintenance. Nat. Rev. Mol. Cell Biol. 10, 243-254. doi: $10.1038 / \mathrm{nrm} 2651$

Nimmakayalu, M. A., Gotter, A. L., Shaikh, T. H., and Emanuel, B. S. (2003). A novel sequence-based approach to localize translocation breakpoints identifies the molecular basis of a $\mathrm{t}(4 ; 22)$. Hum. Mol. Genet. 12, 2817-2825. doi: $10.1093 / \mathrm{hmg} / \mathrm{ddg} 301$

Ohye, T., Inagaki, H., Kato, T., Tsutsumi, M., and Kurahashi, H. (2014). Prevalence of Emanuel syndrome: theoretical frequency and surveillance result. Pediatr. Int. 56, 462-466. doi: 10.1111/ped.12437

Ohye, T., Inagaki, H., Kogo, H., Tsutsumi, M., Kato, T., Tong, M., et al. (2010). Paternal origin of the de novo constitutional $\mathrm{t}(11 ; 22)(\mathrm{q} 23 ; \mathrm{q} 11)$. Eur. J. Hum. Genet. 18, 783-787. doi: 10.1038/ejhg.2010.20

O’Roak, B. J., Vives, L., Girirajan, S., Karakoc, E., Krumm, N., Coe, B. P., et al. (2012). Sporadic autism exomes reveal a highly interconnected protein network of de novo mutations. Nature 485, 246-250. doi: 10.1038/nature 10989
Pearson, C. E., Edamura, K. N., and Cleary, J. D. (2005). Repeat instability: mechanisms of dynamic mutations. Nat. Rev. Genet. 6, 729-742. doi: $10.1038 / \operatorname{nrg} 1689$

Raghavan, S. C., and Lieber, M. R. (2006). DNA structures at chromosomal translocation sites. Bioessays 28, 480-494. doi: 10.1002/bies.20353

Roukos, V., Voss, T. C., Schmidt, C. K., Lee, S., Wangsa, D., and Misteli, T. (2013). Spatial dynamics of chromosome translocations in living cells. Science 341 660-664. doi: 10.1126/science.1237150

Sheridan, M. B., Kato, T., Haldeman-Englert, C., Jalali, G. R., Milunsky, J. M., Zou, Y., et al. (2010). A palindrome-mediated recurrent translocation with 3:1 meiotic nondisjunction: the $\mathrm{t}(8 ; 22)(\mathrm{q} 24.13 ; \mathrm{q} 11.21)$. Am. J. Hum. Genet. 87 , 209-218. doi: 10.1016/j.ajhg.2010.07.002

Sinden, R. R. (1994). DNA Structure and Function. San Diego, CA: Academic Press.

Tan, X., Anzick, S. L., Khan, S. G., Ueda, T., Stone, G., Digiovanna, J. J., et al. (2013). Chimeric negative regulation of p14ARF and TBX1 by a $\mathrm{t}(9 ; 22)$ translocation associated with melanoma, deafness, and DNA repair deficiency. Hum. Mutat. 34, 1250-1259. doi: 10.1002/humu.22354

Tanaka, H., Bergstrom, D. A., Yao, M. C., and Tapscott, S. J. (2005). Widespread and nonrandom distribution of DNA palindromes in cancer cells provides a structural platform for subsequent gene amplification. Nat. Genet. 37, 320-327. doi: $10.1038 / \mathrm{ng} 1515$

Tapia-Páez, I., Kost-Alimova, M., Hu, P., Roe, B. A., Blennow, E., Fedorova, L., et al. (2001). The position of $\mathrm{t}(11 ; 22)(\mathrm{q} 23 ; \mathrm{q} 11)$ constitutional translocation breakpoint is conserved among its carriers. Hum. Genet. 109, 167-177. doi: $10.1007 / \mathrm{s} 004390100560$

Tong, M., Kato, T., Yamada, K., Inagaki, H., Kogo, H., Ohye, T., et al. (2010). Polymorphisms of the 22q11.2 breakpoint region influence the frequency of $d e$ novo constitutional t(11;22)s in sperm. Hum. Mol. Genet. 19, 2630-2637. doi: $10.1093 / \mathrm{hmg} / \mathrm{ddq} 150$

Wang, G., and Vasquez, K. M. (2014). Impact of alternative DNA structures on DNA damage. DNA repair, and genetic instability. DNA Repair. 19, 143-151. doi: 10.1016/j.dnarep.2014.03.017

Conflict of Interest Statement: The authors declare that the research was conducted in the absence of any commercial or financial relationships that could be construed as a potential conflict of interest.

Copyright (c) 2016 Inagaki, Kato, Tsutsumi, Ouchi, Ohye and Kurahashi. This is an open-access article distributed under the terms of the Creative Commons Attribution License (CC BY). The use, distribution or reproduction in other forums is permitted, provided the original author(s) or licensor are credited and that the original publication in this journal is cited, in accordance with accepted academic practice. No use, distribution or reproduction is permitted which does not comply with these terms. 